\title{
Hot topic: Early postpartum treatment of commercial dairy cows with nonsteroidal antiinflammatory drugs increases whole-lactation milk yield
}

\author{
A. J. Carpenter, ${ }^{*}$ C. M. Ylioja, ${ }^{*}$ C. F. Vargas, ${ }^{*}$ L. K. Mamedova, ${ }^{*}$ L. G. Mendonça, ${ }^{*}$ J. F. Coetzee, $\dagger$ L. C. Hollis, ${ }^{*}$ \\ R. Gehring, $\ddagger$ and B. J. Bradford*1 \\ *Department of Animal Sciences and Industry, Kansas State University, Manhattan 66506 \\ †Department of Veterinary Diagnostic and Production Animal Medicine, lowa State University, Ames 50011 \\ łDepartment of Anatomy and Physiology, Kansas State University, Manhattan 66506
}

\begin{abstract}
Previous research has shown that postpartum administration of the nonsteroidal antiinflammatory drug (NSAID) sodium salicylate can increase 305-d milk yield in older dairy cattle (parity 3 and greater). However, in this prior work, sodium salicylate was delivered to cows via the drinking water, a method that does not align well with current grouping strategies on commercial dairy farms. The objective of the current study was to replicate these results on a commercial dairy farm with a simplified treatment protocol and to compare sodium salicylate with another NSAID, meloxicam. Dairy cattle in their second lactation and greater (n $=51$ (treatment) were alternately assigned to 1 of 3 treatments at parturition, with treatments lasting for 3 d. Experimental treatments began 12 to $36 \mathrm{~h}$ after parturition and were (1) 1 placebo bolus on the first day and 3 consecutive daily drenches of sodium salicylate (125 g/cow per day; SAL); (2) 1 bolus of meloxicam (675 mg/cow) and 3 drenches of an equal volume of water (MEL); or (3) 1 placebo bolus and 3 drenches of water $(\mathrm{CON})$. Blood samples were collected on the first day of treatment, immediately following the last day of treatment, and $7 \mathrm{~d}$ after the last day of treatment; plasma was analyzed for glucose, $\beta$-hydroxybutyrate (BHB), free fatty acids, haptoglobin, and paraoxonase. Milk production, body condition score, reproductive status, and retention in the herd were monitored for $365 \mathrm{~d}$ posttreatment, and effects of treatment, parity, days in milk, and interactions were evaluated in mixed effects models. Significance was declared at $P<0.05$. Whole-lactation milk and protein yields were greater in NSAID-treated cows, although 305-d fat production was not affected. There was a significant interaction of treatment and parity for plasma glucose concentration; MEL increased plasma glucose concentrations
\end{abstract}

Received July 2, 2015.

Accepted October 8, 2015.

${ }^{1}$ Corresponding author: bbradfor@ksu.edu compared with CON and SAL in older cows. Sodium salicylate decreased plasma BHB concentration compared with MEL at $7 \mathrm{~d}$ posttreatment, although no difference was detected immediately following treatment. Haptoglobin concentrations were elevated in SAL cows compared with CON. There was a tendency for CON cows to be removed from the herd more quickly than MEL cows (42 vs. $26 \%$ at 365 d posttreatment). Body condition score, concentrations of plasma free fatty acids and paraoxonase, and time to pregnancy were not affected by treatment. These results indicate that NSAID administration in postpartum cows has the potential to be a viable way to improve productivity and potentially longevity in commercial dairies, although further research is necessary to optimize recommendations for producers.

Key words: sodium salicylate, meloxicam, nonsteroidal antiinflammatory drug (NSAID), transition cow

\section{Hot Topic}

Despite ongoing research, the transition period remains a high-risk period for dairy cattle. A growing body of research indicates that systemic metabolic inflammation occurs in dairy cows following parturition and that this inflammation may be linked to negative production outcomes. Bionaz et al. (2007) demonstrated that reduced levels of the liver hydrolase paraoxonase are associated with increased markers of inflammation such as haptoglobin and globulin in early-lactation dairy cattle. Those authors reported that animals in the experiment with the greatest plasma paraoxonase activity during the first $30 \mathrm{~d}$ of lactation produced $10,090 \pm 1,504 \mathrm{~kg}$ of milk in a 305-d lactation, whereas those with the least activity produced $8,119 \pm 2,042 \mathrm{~kg}$, a 1,971-kg difference. Bertoni et al. (2008) reported that cows in the highest quartile of an inflammatory index had decreased milk production in the first month of lactation compared with their counterparts with the lowest inflammatory markers (24.4 vs. $30.9 \pm 2.11 \mathrm{~kg} / \mathrm{d})$. Farney et al. (2013b) administered dairy cattle with the 
nonsteroidal antiinflammatory drug (NSAID) sodium salicylate via drinking water in the week following calving in an attempt to suppress inflammation. Cows in their third lactation and greater that received sodium salicylate produced $21 \%$ more milk over a 305 -d lactation than did parity-matched controls. Interestingly, although the initial hypothesis was that inflammation was linked to suboptimal metabolism, this productivity response occurred even though both the control and treatment groups had low incidence of clinical metabolic disorders.

Meloxicam is another drug in the NSAID class that has high oral bioavailability and a long plasma elimination half-life in cattle compared with sodium salicylate (Coetzee et al., 2009; Malreddy et al., 2013). Although no published studies have demonstrated that meloxicam affects milk production, research in lactating cattle has focused on its use during clinical mastitis (McDougall et al., 2009) and following assisted parturition (Newby et al., 2013). Considering the effect of sodium salicylate on production, it is likely that meloxicam, with a longer elimination half-life, may also have beneficial effects in lactation after a single dose. Therefore, the objective of this study was to determine if NSAID treatment in the first days following parturition would positively affect milk production and health of cows on a commercial dairy farm.

Multiparous cows from a commercial dairy $(\mathrm{n}=51$ / treatment) were enrolled in the study 12 to $36 \mathrm{~h}$ after calving. Animals were managed similarly throughout the dry period and early lactation. Cows assigned to sodium salicylate treatment (SAL) received a placebo bolus on d 1 of treatment and an oral drench containing $125 \mathrm{~g} / \mathrm{d}$ of sodium salicylate (estimated to be approximately $185 \mathrm{mg} / \mathrm{kg}$ of BW; Wintersun Chemical, Ontario, CA) in $375 \mathrm{~mL}$ of water for 3 consecutive days beginning on $\mathrm{d} 1$ of treatment. Cows assigned to meloxicam treatment (MEL) received $675 \mathrm{mg}$ of meloxicam (estimated to be approximately $1 \mathrm{mg} / \mathrm{kg}$ of BW; Unichem Pharmaceuticals, Rochelle Park, NJ) as a bolus on $\mathrm{d} 1$ of treatment as well as 3 consecutive daily drenches of $375 \mathrm{~mL}$ of water. Control cows (CON) received a placebo bolus on $\mathrm{d} 1$ and water drenches $(375$ $\mathrm{mL}$ ) for $3 \mathrm{~d}$. The placebo and meloxicam boluses both contained casein as a filler. Only cows entering their second lactation and greater were enrolled in the study $(\mathrm{CON}=18$ cows in parity 2 and 33 cows in parity $\geq 3$; $\mathrm{MEL}=27$ cows in parity 2 and 24 cows in parity $\geq 3$; $\mathrm{SAL}=20$ cows in parity 2 and 31 cows in parity $\geq 3$ ). Cows were blocked by mastitis at parturition $(\mathrm{CON}=$ $1, \mathrm{MEL}=2, \mathrm{SAL}=2)$, breed $(\mathrm{CON}=6, \mathrm{MEL}=6$, $\mathrm{SAL}=4$ crossbred; all others were Holstein), dystocia (calving difficulty score $\geq 3 ; \mathrm{CON}=5, \mathrm{MEL}=5$, SAL
$=6)$, and twin births $(\mathrm{CON}=4, \mathrm{MEL}=4, \mathrm{SAL}=$ 3 ) and were sequentially assigned to treatment within block between July 15 and September 2, 2013. Mastitis was determined by farm staff for blocking purposes, and was defined as clinical mastitis with abnormal appearance of milk, such as clots. Milk from treated cows was discarded for $10 \mathrm{~d}$ after the start of treatment to ensure that no drug residue entered the saleable milk stream, particularly for meloxicam (Malreddy et al., 2013).

Blood samples were collected via the coccygeal vein on the first and last day of treatment and $7 \mathrm{~d}$ after the completion of treatment. Plasma was collected and stored at $-20^{\circ} \mathrm{C}$ until analyzed for glucose by a colorimetric kit (kit \#439-90901; Wako Chemicals USA Inc.), free fatty acids using an enzymatic colorimetric procedure (NEFA-HR; Wako Chemicals USA Inc., Richmond, VA), and BHB using a commercial kit (kit \#H7587-58; Pointe Scientific Inc., Canton, MI). Haptoglobin was measured by the method of Cooke and Arthington (2013), a colorimetric technique that uses differences in peroxidase activity to measure haptoglobin-hemoglobin complexing. Absorbance was measured with a spectrophotometer (PowerWave XS; BioTek Instruments Inc., Winooski, VT) and calculations were performed using Gen5 software (BioTek Instruments Inc.). Paraoxonase was measured by the method of Ferré et al. (2002).

Reproduction and culling data were recorded in PCDart (Dairy Records Management Services, Raleigh, NC) by the farm staff, who were blinded to treatments. Reasons for culling were grouped into the following 7 categories: injury, lameness, low milk, mastitis, SCC, unknown, and other disease. Milk weights were collected electronically at each milking and stored in PCDart. Milk composition (including SCC) and yield were tested for individual cows at approximately 6 -wk intervals by DHIA technicians, and 305-d mature-equivalent lactation yields were calculated by DHIA for animals that remained in the herd for at least $90 \mathrm{~d}$. Body condition score was recorded as the average of responses from at least 3 independent observers on the last day of treatment (3 d after enrollment) and approximately 2, 5 , and 8 mo following enrollment.

Statistical analyses were carried out using SAS (version 9.3; SAS Institute Inc., Cary, NC) and JMP (version 10; SAS Institute Inc.). Plasma variables were analyzed using d-0 values as a covariate along with fixed effects of block, parity (2 or $3+$ ), treatment, sample day, and treatment by day interaction, and the random effect of cow. Milk data were analyzed with fixed effects of block, parity, treatment, week of lactation, and treatment $\times$ week interaction, along with the random effects 
of cow and week of the year. Both models accounted for repeated measures over time with autoregressive covariance structures. This covariance structure was selected based on Bayesian information criterion (BIC) values. Blocking factors and treatment $\times$ block interactions were tested and removed from models when $P>0.10$. Additionally, d-0 covariate values (plasma analytes and $\mathrm{BCS}$ ) and their interactions with treatment were tested in models for milk yield, but all were removed because they were not significant predictors. To assess treatment effects on SCS, cows with mastitis at enrollment $(\mathrm{n}=5)$ were excluded, and then individual test-day values between 4 and 305 DIM were modeled with linear and quadratic DIM terms (the cubic term was not significant), treatment, and treatment $\times$ DIM interaction, as well as the random effect of cow. Mastitis at enrollment was included in the statistical model for all responses other than SCS.

In addition to milk responses by week, 305-d matureequivalent lactation yields were evaluated as described by Farney et al. (2013b), using the PTA for the applicable component as a covariate to account for genetic differences; 122 cows had the requisite data and were used for this analysis. Survival analysis was used to assess treatment effects on retention in the herd and time to pregnancy. Pregnancy date was determined based on breeding dates when pregnancy was confirmed by ultrasound $65 \mathrm{~d}$ postinsemination, and cows that left the herd before $365 \mathrm{~d}$ postcalving were censored from pregnancy analysis on that date. Wilcoxon Chi-squared tests were used to assess differences between treatments for survival curves. Incidence of specific disorders and pregnancy on first service were evaluated by pairwise Fisher's exact tests. Significance was declared at $P<$ 0.05 and tendencies at $0.05 \leq P<0.10$.

Both MEL and SAL increased daily milk production compared with $\mathrm{CON}(P<0.05 ; 36.8,36.3$, and $32.8 \pm 2.2 \mathrm{~kg} / \mathrm{d}$, respectively). We found no evidence of treatment interactions with time $(P=0.56)$, although the contrasts between NSAID treatments and CON did not become significant until $7 \mathrm{wk}$ in milk (Figure 1A). Analysis of 305-d mature-equivalent milk yield resulted in similar findings, with MEL and SAL increasing yields compared with CON (both $P<0.03 ; 11,205$, 11,411 , and $10,472 \pm 486 \mathrm{~kg}$, respectively). Similar results were observed when daily and 305-d data were analyzed after removing cows with mastitis at parturition $(P<0.05$ for all contrasts with $\mathrm{CON}$, except SAL vs. CON for daily yield: $P=0.06)$. Figure $1 \mathrm{~B}$ shows 305-d mature-equivalents yields for milk fat and milk protein. No differences were observed for milk fat yield $(P=0.13)$ but protein yields were increased by each NSAID treatment $(P<0.05)$. We observed an interac- tion between treatment and DIM for SCS $(P=0.02$, Figure $1 \mathrm{C}$ ), with the results suggesting that NSAID treatments decreased SCS in the first several months of lactation. However, when the data set was limited to values measured in the first 50 DIM, a simple NSAID treatment contrast (CON vs. MEL + SAL) was not significant $(P=0.13)$.

The increase in milk production is consistent with the response observed by Farney et al. (2013b). A few other experiments have assessed blanket treatment with NSAID in postpartum cows. Bertoni et al. (2004) gave acetyl-salicylate to cows for the first 5 DIM and saw a tendency for increased peak milk yield. Priest et al. (2013) gave carprofen as a blanket NSAID treatment to multiparous cows 21 to $31 \mathrm{~d}$ after calving and saw no effect on milk production. The authors hypothesized that this was due to the delay in treatment after calving. In a follow-up study, Meier et al. (2014) reported that whether NSAID treatment was administered beginning $1 \mathrm{~d}$ following calving or $19 \mathrm{~d}$, there was no difference between control and NSAID groups for milk production. In an experiment reported by Shwartz et al. (2009), 26 cows received either intravenous flunixin meglumine or saline for the first 3 DIM. In the first 7 $\mathrm{d}$ of lactation, milk yield was decreased for cows receiving NSAID treatment, although there was no overall effect on milk yield up to 35 DIM. One study that administered injectable meloxicam as a blanket treatment postcalving showed no effect on milk production (Mainau et al., 2014).

There are several possible explanations for variability in the reported milk responses to NSAID treatments. Meier et al. (2014) attributed the difference in results between their experiment and those of Bertoni et al. (2004) and Farney et al. (2013b) to the differences in mode of action between different NSAID treatments. This is a valid differentiation between their results and responses to salicylates; however, it does not explain the differences between our results and those of Mainau et al. (2014), in which meloxicam was also used as a blanket treatment in early-lactation dairy cattle. This could be attributed to differences in sample size $(\mathrm{n}=$ 51 vs. $\mathrm{n}=30$ ), although there are other differences between these experiments. The method of meloxicam administration differed; in our experiment, meloxicam was given orally, whereas Mainau et al. (2014) injected meloxicam. Although BW was not measured in our experiment, if it is assumed that the average BW of cows on this study was approximately $680 \mathrm{~kg}$, our dose of $675 \mathrm{mg}$ would be approximately double the dosage of $0.5 \mathrm{mg} / \mathrm{kg}$ used by Mainau et al. (2014). Another difference between the current experiment and that of Mainau et al. is the timing of treatment administration 
A
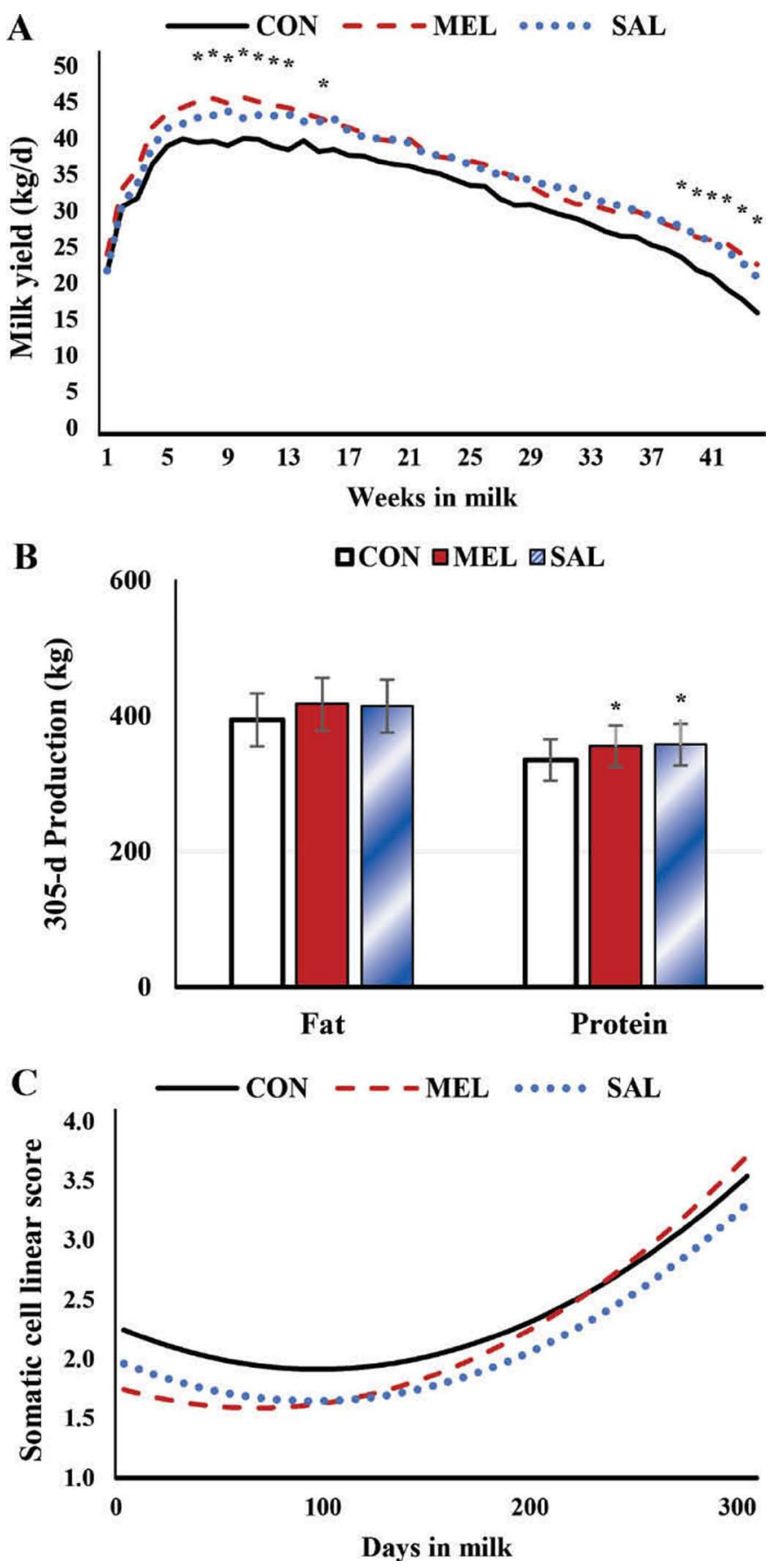

Figure 1. Whole-lactation milk responses following early-lactation treatment with placebo $(\mathrm{CON})$, meloxicam (MEL), or sodium salicylate (SAL). Treatments were administered for $3 \mathrm{~d}$ beginning 12 to $36 \mathrm{~h}$ postpartum, and values are means \pm SEM. (A) Daily milk yield data were compiled by week and analyzed with repeated measures (pooled $\mathrm{SEM}=2.4 \mathrm{~kg} / \mathrm{d}) .{ }^{*}$ NSAID treatments differ from CON $(P<0.05, \mathrm{n}$ $=51$ ). (B) 305-d mature-equivalent component yields were analyzed in a model that accounted for genetic effects. ${ }^{*}$ Differs from CON $(P$ $<0.05, \mathrm{n}=39-42)$. (C) Individual test-day SCS data were modeled to account for DIM and cow $(\mathrm{n}=49-50)$. Treatment interacted with DIM to influence SCS, due to a different treatment $\times$ DIM coefficient for MEL versus SAL $(P=0.02)$. As an example, the equation for SAL was $\mathrm{SCS}=1.27+0.0032 \times \mathrm{DIM}+0.0000378 \times(\mathrm{DIM}-137.9)^{2}$. Color version available online.
(12-36 h postcalving vs. a maximum of $6 \mathrm{~h}$ postcalving).

Perhaps the most important confounding effect on results of NSAID trials is the duration of milk production measurement. In the current experiment, statistical tendencies were detected beginning at $4 \mathrm{wk}$ in milk $(P=0.07)$, and significance was not detected until 7 wk in milk $(P=0.02)$. Priest et al. (2013) and Meier et al. (2014) measured milk production for $6 \mathrm{wk}$. Milk production was monitored for 5 wk by Shwartz et al. (2009). Mainau et al. (2014) reported milk production over 1 mo. It is possible that some of the discrepancy between the current experiment and these previously published reports is because milk production was not monitored long enough to detect any differences in previous studies.

It is important to note that both NSAID treatments necessitated the discarding of milk to prevent the sale of milk contaminated by drug residues. There are no official guidelines in the United States for disposal of milk following salicylate or meloxicam treatment in lactating cows. However, based on the short half-life of salicylate, a milk withdrawal time of $24 \mathrm{~h}$ is considered adequate to avoid residues (US Pharmacopeia, 2004). In contrast, the recently approved use of injectable meloxicam at $0.5 \mathrm{mg} / \mathrm{kg}$ of BW for mastitis in Canada requires a 4-d withdrawal, and oral meloxicam at $1 \mathrm{mg} / \mathrm{kg}$ of BW (approximately the dose used herein) resulted in undetectable residues in milk by $80 \mathrm{~h}$ posttreatment (Malreddy et al., 2013). Although these data suggest that a 4- or 5-d withdrawal is likely adequate for avoiding residues following meloxicam treatment, we discarded milk for $10 \mathrm{~d}$ to remove any uncertainty about residue avoidance. The increased 305-d milk production that we observed can compensate for loss of milk revenue during the withdrawal period, but the inconvenience of segregating milk from these cows could limit adoption of postpartum NSAID treatment on dairies. On the other hand, several commonly used dry cow antibiotic therapies require that milk be discarded for the first 3 to 4 DIM (Royster and Wagner, 2015), and the gland is transitioning from colostrum to mature milk secretion during this time, making the product of poor quality for dairy products anyway. Considering this, the SAL protocol would add only 1 to $2 \mathrm{~d}$ and MEL only 2 to 3 $\mathrm{d}$ of additional milk discarding.

We found no effect of treatment on blood glucose concentration in second-parity cows, but MEL increased plasma glucose concentrations in older cows compared with CON and SAL $(P<0.05$; treatment $\times$ parity: $P<0.05$; Figure $2 \mathrm{~A}$ ). Although plasma BHB concentrations were similar across treatments at the end of the treatment period $(P>0.1)$, SAL decreased plasma BHB concentration compared with MEL at $7 \mathrm{~d}$ 

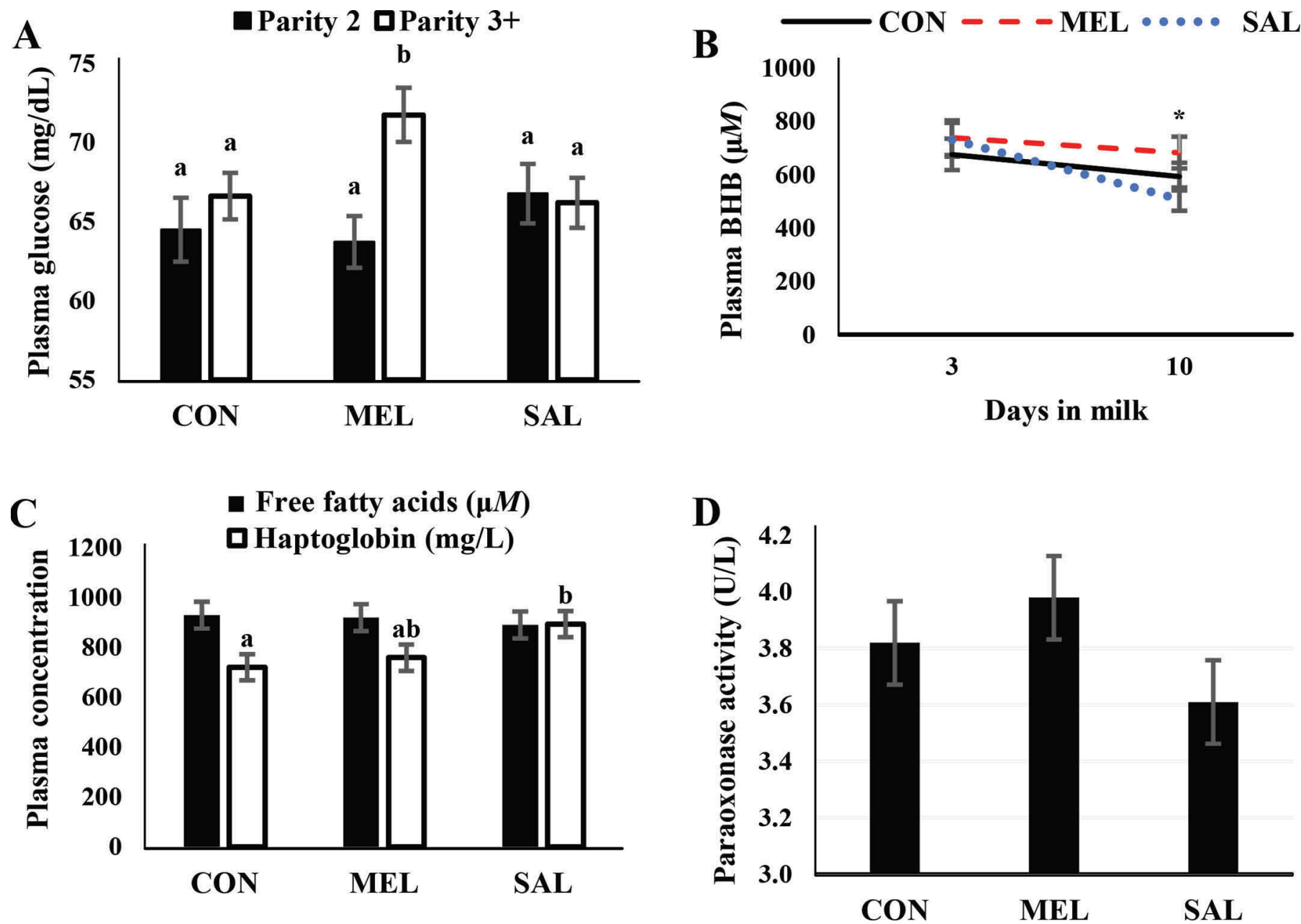

Figure 2. Plasma constituent responses following early-lactation treatment with placebo (CON), meloxicam (MEL), or sodium salicylate (SAL). Treatments were administered for $3 \mathrm{~d}$ beginning 12 to $36 \mathrm{~h}$ postpartum. Unless otherwise noted, values represent the overall mean $( \pm$ SEM, $\mathrm{n}=50-51)$ across samples collected at 3 and 10 DIM, and means with different letters $(\mathrm{a}, \mathrm{b})$ differ $(P<0.05)$. (A) Plasma glucose concentration was increased by MEL in parity $3+$ cows. (B) Treatment interacted with time to alter plasma BHB concentration. ${ }^{*}$ SAL differs from MEL at d 7 post-treatment $(P=0.02)$. (C) Plasma free fatty acids concentration was not altered by treatment, but SAL increased haptoglobin concentration compared with CON. (D) Plasma paraoxonase activity was unaltered by treatment. Color version available online.

posttreatment $(P=0.02$; treatment $\times$ day: $P<0.05$; Figure 2B). Plasma free fatty acid concentrations were not affected by treatment $(P=0.8$; Figure $2 \mathrm{C})$. No other interactions were significant for free fatty acids, glucose, or BHB $(P>0.1)$. Neither plasma variables nor BCS measured on d 1 was a significant predictor of any of the outcomes measured $(P>0.1)$.

The time points for blood sample collection were chosen based on the results of Farney et al. (2013a), which showed that glucose, BHB, and some signaling molecules were significantly altered by NSAID treatment on either the final day of treatment or $7 \mathrm{~d}$ posttreatment. They reported that cows in third parity and greater experienced hypoglycemia at the end of $7 \mathrm{~d}$ of sodium salicylate treatment, even though they also had increased 305-d milk production. The SAL treatment regimen in the current experiment did not induce the same response, possibly because of the shorter treatment window. The elevation in blood glucose after meloxicam treatment in older cows in the current study is unique in the literature. Blood glucose was not measured in every experiment, and Newby et al. (2013) observed no changes in glucose levels. Unlike in the current experiment, BHB levels increased after treatment with sodium salicylate in Farney et al. (2013a), consistent with the hypoglycemia reported in that paper. Although there were no differences between CON and either NSAID treatment in the current experiment, SAL and MEL groups differed in BHB concentration, suggesting subtle differences in responses to different 
NSAID treatments. The failure to demonstrate a consistent pattern of blood metabolites between MEL and SAL would seem to indicate that the differences observed in milk production are due to something beyond simple transition health, perhaps a programming effect. Paraoxonase did not differ between treatments $(P=$ 0.15 ; Figure 2D), although surprisingly, haptoglobin levels were elevated in SAL cows compared with CON $(P=0.02)$, with levels in MEL being intermediate (Figure $2 \mathrm{C}$ ). Proinflammatory eicosanoids were elevated 7 $\mathrm{d}$ following the cessation of NSAID treatment in the study reported by Farney et al. (2013a). Those authors attributed this to a "rebound" effect of the inflammatory response after the antiinflammatory agent was removed. Though there was no interaction between treatment and time for haptoglobin or paraoxonase in the current study, it is possible that the "homeostatic target" for the inflammatory response postulated by these authors contributed to the differences in haptoglobin levels. It is important to recognize that not all metabolic changes may have been captured in the sampling time selected for the current experiment, and it may be advisable in future studies to monitor blood metabolites for longer than the 7-d posttreatment period chosen in the current experiment.

We detected a tendency for CON cows to leave the herd more quickly than MEL cows over the first 365 d postenrollment ( $P=0.06 ; 21$ vs. 13 gone by $365 \mathrm{~d}$, Figure $3 \mathrm{~A}$ ). There was a tendency for CON to differ from MEL in "other disease" incidence $(P=0.09)$, a category that includes periparturient metabolic disorders, as only 2 cows in MEL were removed for this reason, compared with 8 cows in $\mathrm{CON}$ and 6 cows in SAL. No other statistical differences or tendencies were detected for other culling categories $(P>0.1$; data not shown). Interestingly, no SAL cows were culled for low milk production, although 4 and 3 cows left the herd for this reason from CON and MEL groups, respectively. The incidence of culling due to mastitis was similar across treatment groups, with 2,1 , and 4 cows culled for mastitis in CON, MEL, and SAL treatments, respectively, suggesting that observed treatment effects on SCS dynamics (Figure 1C) did not translate into different clinical mastitis outcomes. We observed no difference between treatments for the time to pregnancy $(P=0.68$; Figure $3 \mathrm{~B})$, and no differences in first-service pregnancy rate $(P>0.78 ; 21.3 \%$ overall $)$. No differences were observed in BCS $(P=0.93$, Figure $3 \mathrm{C})$, and there was no interaction between treatment and time (treatment $\times$ time: $P=0.76$ ).

Few studies have directly analyzed the long-term effects of NSAID administration in the transition period on reproductive performance. Those that have focused on the transition period have generally investigated the
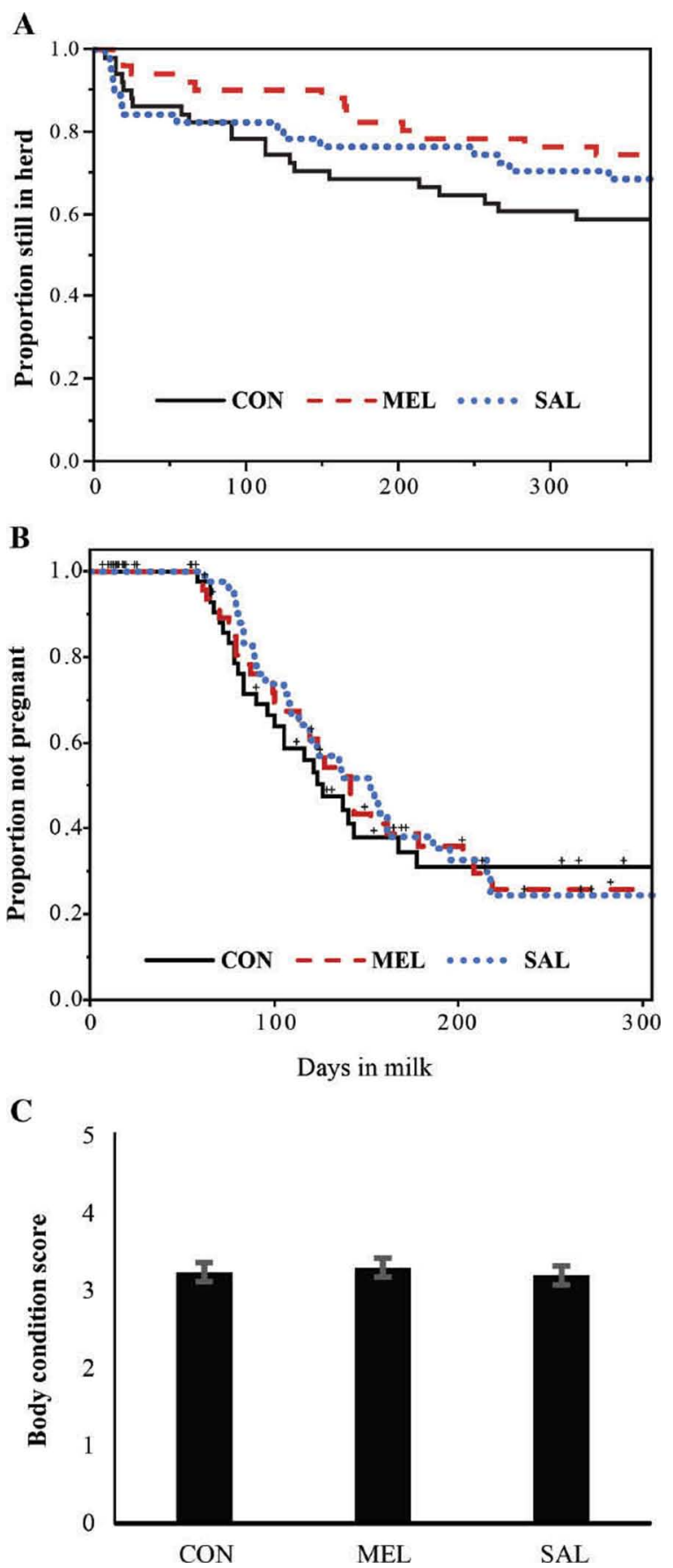

Figure 3. Survival analysis and BCS responses following early-lactation treatment with placebo $(\mathrm{CON})$, meloxicam (MEL), or sodium salicylate (SAL). Treatments were administered for $3 \mathrm{~d}$ beginning 12 to $36 \mathrm{~h}$ postpartum $(\mathrm{n}=51)$. (A) Retention in the herd by treatment; 30,38 , and 35 cows remained in the herd at $365 \mathrm{~d}$ posttreatment for CON, MEL, and SAL, respectively. MEL tended to delay removal from the herd relative to CON ( $P=0.06$, Wilcoxon chi-squared test). (B) Pregnancy survival analysis showed no effect of treatment on mean time to pregnancy $(P>0.78) .{ }^{+}$Cows removed from the herd were censored from analysis. (C) BCS was evaluated on d 3 of treatment and approximately 2,5 , and 8 mo posttreatment. No treatment $\times$ time interaction was detected $(P=0.76)$, and values represent the overall means ( \pm SEM, $\mathrm{n}=50-51)$. No treatment effect was detected $(P=0.93)$. Color version available online. 
use of NSAID as a therapeutic treatment for metritis. One concern regarding NSAID treatment too soon after calving is that the incidence of retained fetal membranes could be elevated; however, evidence suggests that its use does not increase the percentage of cows with retained placenta following meloxicam administration, even immediately after calving (Newby, 2014). Amiridis et al. (2001) demonstrated that cows treated for metritis with flunixin at 5 to 8 DIM had shorter intervals to first estrous, and uterine involution occurred more rapidly in these cows. Priest et al. (2013) reported that cows with subclinical metritis responded to treatment with the NSAID carprofen at 21 to 31 DIM with increased pregnancy rates 4 wk after the planned start of mating, whereas cows with normal to moderate uterine pathology did not respond in this way to NSAID. Alternatively, Drillich et al. (2007) reported no difference in first-service conception rate in cows with metritis that received flunixin plus an antibiotic compared with an antibiotic alone. When carprofen was administered after a voluntary waiting period, other researchers have reported no effect of carprofen on reproduction when administered 14 to $16 \mathrm{~d}$ after insemination (von Krueger and Heuwieser, 2010) or both before and after insemination (Heuwieser et al., 2011). Other researchers have shown no benefit of flunixin in combination with timed insemination (Rabaglino, 2010). When meloxicam was delivered intramuscularly at various time points surrounding breeding and throughout pregnancy, no differences in reproductive performance were observed (Hirsch and Philipp, 2009). Considering the positive effects of NSAID treatment on reproduction that other authors have observed, it is possible, if an NSAID effect is more potent in cows with metritis, that the number of cows with uterine infections was inadequate to detect a treatment effect in the current experiment.

In conclusion, early-lactation treatment with NSAID from 2 different classes increased whole-lactation milk yield by 7 to $9 \%$, with only a 3 -d treatment window. When possible, NSAID effects should be recorded throughout the entire lactation, as treatment differences may be delayed and not immediately apparent following administration, such as in the current experiment. Furthermore, the tendency for MEL to delay the mean time to removal from the herd points to a fruitful area of investigation for future research.

\section{ACKNOWLEDGMENTS}

This paper is contribution no. 15-440-J from the Kansas Agricultural Experiment Station (Manhattan). The authors extend their sincere thanks to Prairieland Dairy LLC (Firth, NE) for their assistance and pa- tience with this project, and to Church and Dwight Co. (Princeton, NJ) for partial financial support of this work. A provisional patent, application number 62/047,349, was filed on 24 September 2014.

\section{REFERENCES}

Amiridis, G. S., L. Leontides, E. Tassos, P. Kostoulas, and G. C. Fthenakis. 2001. Flunixin meglumine accelerates uterine involution and shortens the calving-to-first-oestrus interval in cows with puerperal metritis. J. Vet. Pharmacol. Ther. 24:365-367.

Bertoni, G., E. Trevisi, X. Han, and M. Bionaz. 2008. Effects of inflammatory conditions on liver activity in puerperium period and consequences for performance in dairy cows. J. Dairy Sci. 91:3300 3310 .

Bertoni, G., E. Trevisi, and F. Piccioli-Cappelli. 2004. Effects of acetyl-salicylate used in post-calving of dairy cows. Vet. Res. Commun. 28:217-219.

Bionaz, M., E. Trevisi, L. Calamari, F. Librandi, A. Ferrari, and G. Bertoni. 2007. Plasma paraoxonase, health, inflammatory conditions, and liver function in transition dairy cows. J. Dairy Sci. 90:1740-1750.

Coetzee, J. F., B. Kukanich, R. Mosher, and P. S. Allen. 2009. Pharmacokinetics of intravenous and oral meloxicam in ruminant calves. Vet. Ther. 10:1-4

Cooke, R. F., and J. D. Arthington. 2013. Concentrations of haptoglobin in bovine plasma determined by ELISA or a colorimetric method based on peroxidase activity. J. Anim. Physiol. Anim. Nutr. (Berl.) 97:531-536.

Drillich, M. V., D. Voigt, D. Forderung, and W. Heuwieser. 2007. Treatment of acute puerperal metritis with flunixin meglumine in addition to antibiotic treatment. J. Dairy Sci. 90:3758-3763.

Farney, J. K., L. K. Mamedova, J. F. Coetzee, B. KuKanich, L. M. Sordillo, S. K. Stoakes, J. E. Minton, L. C. Hollis, and B. J. Bradford. 2013a. Anti-inflammatory salicylate treatment alters the metabolic adaptations to lactation in dairy cattle. Am. J. Physiol. Regul. Integr. Comp. Physiol. 305:R110-R117.

Farney, J. K., L. K. Mamedova, J. F. Coetzee, J. E. Minton, L. C. Hollis, and B. J. Bradford. 2013b. Sodium salicylate treatment in early lactation increases whole-lactation milk and milk fat yield in mature dairy cows. J. Dairy Sci. 96:7709-7718.

Ferré, N., J. Camps, E. Prats, E. Vilella, A. Paul, L. Figuera, and J. Joven. 2002. Serum paraoxonase activity: a new additional test for the improved evaluation of chronic liver damage. Clin. Chem. 48:261-268

Heuwieser, W., M. Iwersen, and L. Goetze. 2011. Efficacy of carprofen on conception rates in lactating dairy cows after subcutaneous or intrauterine administration at the time of breeding. J. Dairy Sci. 94:146-151.

Hirsch, A. C., and H. Philipp. 2009. Effects of meloxicam on reproduction parameters in dairy cattle. J. Vet. Pharmacol. Ther. 32:566570.

Mainau, E., A. Cuevas, J. L. Ruiz-de-la-Torre, E. Abbeloos, and X. Manteca. 2014. Effect of meloxicam administration after calving on milk production, acute phase proteins, and behavior in dairy cows. J. Vet. Behav. 9:357-363.

Malreddy, P. R., J. F. Coetzee, B. Kukanich, and R. Gehring. 2013. Pharmacokinetics and milk secretion of gabapentin and meloxicam co-administered orally in Holstein-Friesian cows. J. Vet. Pharmacol. Ther. 36:14-20.

McDougall, S., M. A. Bryan, and R. M. Tiddy. 2009. Effect of treatment with the nonsteroidal antiinflammatory meloxicam on milk production, somatic cell count, probability of re-treatment, and culling of dairy cows with mild clinical mastitis. J. Dairy Sci. 92:4421-4431.

Meier, S., N. V. Priest, C. R. Burke, J. K. Kay, S. McDougall, M. D. Mitchell, C. G. Walker, A. Heiser, J. J. Loor, and J. R. Roche. 2014. Treatment with a nonsteroidal antiinflammatory drug after calving did not improve milk production, health, or reproduction 
parameters in pasture-grazed dairy cows. J. Dairy Sci. 97:29322943.

Newby, N. C., D. L. Pearl, S. J. LeBlanc, K. E. Leslie, M. A. G. von Keyserlingk, and T. F. Duffield. 2013. Effects of meloxicam on milk production, behavior, and feed intake in dairy cows following assisted calving. J. Dairy Sci. 96:3682-3688.

Newby, N. C., D. Renaud, R. Tremblay, and T. F. Duffield. 2014. Evaluation of the effects of treating dairy cows with meloxicam at calving on retained fetal membranes risk. Can. Vet. J. 55:11961199 .

Priest, N. V., S. McDougall, C. R. Burke, J. R. Roche, M. Mitchell, K. L. McLeod, S. L. Greenwood, and S. Meier. 2013. The responsiveness of subclinical endometritis to a nonsteroidal antiinflammatory drug in pasture-grazed dairy cows. J. Dairy Sci. 96:4323-4332.

Rabaglino, M. B., C. A. Risco, M.-J. Thatcher, F. Lima, J. E. P. Santos, and W. W. Thatcher. 2010. Use of a five-day progester- one-based timed AI protocol to determine if flunixin meglumine improves pregnancy per timed AI in dairy heifers. Theriogenology 73:1311-1318.

Royster, E., and S. Wagner. 2015. Treatment of mastitis in cattle. Vet. Clin. North Am. Food Anim. Pract. 31:17-46.

Shwartz, G., K. L. Hill, M. J. VanBaale, and L. H. Baumgard. 2009 Effects of flunixin meglumine on pyrexia and bioenergetic variables in postparturient dairy cows. J. Dairy Sci. 92:1963-1970.

US Pharmacopeia. 2004. USP Veterinary pharmaceutical information monographs - Anti-inflammatories. J. Vet. Pharmacol. Ther. 27(Suppl. 1):6-14.

von Krueger, X., and W. Heuwieser. 2010. Effect of flunixin meglumine and carprofen on pregnancy rates in dairy cattle. J. Dairy Sci. 93:5140-5146. 